\section{Key points}

I Asthma is one of the most common diseases complicating pregnancy.

I Pregnancy influences the control of asthma; its effect may be beneficial or detrimental.

I Asthma during pregnancy should be treated according to its severity in a step-wise manner and as aggressively as asthma in nonpregnant patients.

It is safer for pregnant women with asthma to be treated with asthma medications than to have asthma symptoms and exacerbations.

I Uncontrolled and severe asthma is associated with adverse pregnancy outcomes for both mother and foetus.

I Frequent monitoring, severity-based pharmacotherapy, and prevention and prompt treatment of exacerbations are very important for the safe delivery of a healthy baby.

I Breastfeeding is strongly recommended for asthmatic females; it is associated with a reduction in the development of atopy in children, and the use of asthma medications is safe during breastfeeding.

Integrated care (obstetrics and pulmonary), patient education, compliance with treatment and avoidance of triggering factors are key issues in the management of a pregnant asthmatic patient. 


\section{Asthma and pregnancy: interactions and management}

\section{Educational aims}

1 To describe interactions between asthma and pregnancy.

1 To present management guidelines and discuss the use of specific asthma medications during pregnancy.

\section{Summary}

Asthma is one of the most common diseases complicating pregnancy. It can lead to significant morbidity for both mother and foetus. Pregnancy may also affect asthma control and severity. Therefore, pregnant asthmatic patients should receive integrated obstetric and respiratory care.

The focus of asthma treatment remains the control of symptoms and maintenance of normal lung function of the mother. However, during pregnancy, the safe delivery of a healthy baby is an additional goal. It is safer for pregnant women with asthma to be treated with asthma medications than for them to have asthma symptoms and exacerbations.

Asthma treatment during pregnancy follows the same step-wise approach as normal, and studies have shown that first-line asthma medications (such as inhaled glucocorticosteroids and $\beta_{2}$-agonists) are not associated with an increased incidence of foetal abnormalities. Moreover, inhaled glucocorticosteroids have been shown to prevent exacerbations of asthma in pregnancy and should be used in persistent asthma to control the disease and prevent exacerbations. If acute exacerbations develop, they should be treated promptly and aggressively in order to avoid foetal hypoxia.

Good pregnancy and asthma outcomes are achieved through integrated obstetric and respiratory care, close monitoring, meticulous tailoring of pharmacotherapy, patient education and reassurance. This review describes interactions between asthma and pregnancy and briefly presents treatment guidelines.

Asthma is one of the most common diseases that complicate pregnancy: up to $8.4 \%$ of pregnancies may be complicated by asthma $[1,2]$. The disease may affect pregnancy outcomes and lead to significant morbidity for both mother and foetus. Pregnancy may also induce changes and affect the severity and control of asthma, and it seems that pregnant females with moderate-to-severe asthma tend to suffer a deterioration in their condition and experience exacerbations.

Mild-to-moderate asthma can be associated with excellent maternal and perinatal pregnancy outcomes, especially if patients are managed according to contemporary guidelines and recommendations. However, severe
The ERS designates this

educational activity for a

maximum of 1 CME credit. For

information on how to earn

CME credits, see page 315.
M. Gaga ${ }^{1,2}$
E. Oikonomidou 1,2
E. Zervas ${ }^{1,3}$
N. Papageorgiou-Georgatou 1,4

${ }^{1}$ Asthma Centre, 27 th Respiratory Medicine Dept, and 45th Respiratory Medicine Dept, Athens Chest Hospital "Sotiria", Athens, and ${ }^{3}$ Respiratory Medicine Dept, Korinthos General Hospital, Corinth, Greece.

\section{Correspondence: \\ M. Gaga \\ 7th Respiratory Medicine Dept and Asthma Centre \\ "Sotiria" Hospital \\ 152 Mesogion Avenue \\ Athens 11527 \\ Greece \\ Fax: 302107781911 \\ E-mail:mgaga@med.uoa.gr}

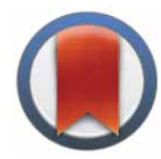

CrossMark $\leftarrow$ click for updates 


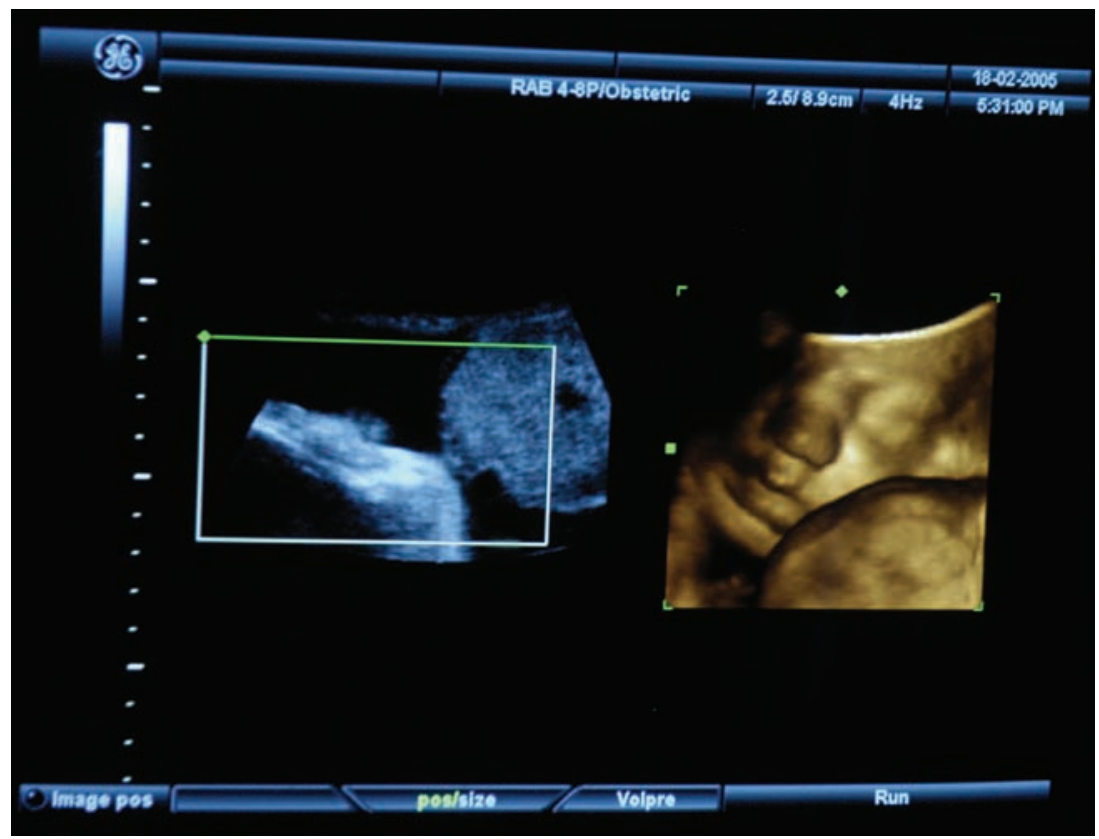

and poorly controlled asthma may be associated with a number of severe adverse outcomes, including foetal death, pre-term labour and mild prematurity, low birth weight, preeclampsia, gestational diabetes, ante- and postpartum haemorrhage and increased need for caesarian section $[3,4]$. Therefore, pregnant women with uncontrolled asthma are a high-risk group, who need to be monitored closely and treated optimally. Studies examining the effect of firstline asthma medications, i.e. inhaled steroids and short-acting $\beta$-agonists, have not shown risks induced to the foetus. This evidence is summarised in the current National Asthma Education and Prevention Program (NAEPP) and Global Initiative for Asthma (GINA) guidelines $[2,5]$ which state that:

$>$ it is safer for pregnant women with asthma to be treated with asthma medications than for them to have asthma symptoms and exacerbations; and

$>$ inadequate control of asthma is a greater risk to the foetus than asthma medications.

Cooperation between pulmonary specialists and obstetricians and midwives is very important, as the pregnant woman is likely to seek the obstetrician's/midwife's advice on asthma treatment, especially regarding the safety of medication during pregnancy. Obstetric health providers should encourage regular treatment, stress the importance of regular respiratory follow-up and reassure the gravid asthmatic patient that the outcome of pregnancy is excellent in well-controlled asthma.

\section{Physiological changes during pregnancy}

Most respiratory physiological changes occur due to enhanced production of hormones [6]. For example, during pregnancy, levels of progesterone, oestradiol and cortisol increase. Progesterone increases minute ventilation and decreases pulmonary vascular resistance, but it also affects $\beta_{2}$-adrenoreceptor responsiveness and airway inflammation

Changes in lung function include a reduction of functional residual capacity (FRC) and residual volume (RV), and an increase in inspiratory capacity (IC), while forced expiratory volume in one second (FEV1) and vital capacity (VC) are preserved [7-9]. Due to the increased minute ventilation (by 20-40\%), blood gases change significantly and arterial oxygen tension $\left(\mathrm{Pa}_{1} \mathrm{O}_{2}\right)$ rises to 13.3-14.0 kPa (100-105 mmHg), while the carbon dioxide tension in arterial blood $\left(\mathrm{Pa}_{1} \mathrm{CO}_{2}\right)$ falls to $4.26-4.52 \mathrm{kPa}(32-34 \mathrm{mmHg})$. $\mathrm{pH}$ is maintained by increased renal excretion of bicarbonate. No significant changes in dynamic volumes are observed during pregnancy while limited data exist regarding changes in airway hyperresponsiveness. JUNIPER et al. [10] demonstrated an overall improvement in airway responsiveness to methacholine challenge in the second trimester compared with pre-conception in 16 subjects, but no significant changes in $\mathrm{FEV} 1$ or $\mathrm{FEV} 1 / \mathrm{VC}$ were observed. Any changes in $\mathrm{FEV}_{1}$, the $\mathrm{FEV} /$ /forced vital capacity (FVC) ratio or flow rates are therefore the result of respiratory pathology and should alert the physician.

Shortness of breath or an increased awareness of breathing may be present during pregnancy, especially in the third trimester. This is attributed to either increased work of breathing or increased respiratory drive, and it is normal. Furthermore, nasal obstruction is common during pregnancy and is due to hyperaemia and oedema. Nasal obstruction accentuates the sensation of breathlessness. It is important to differentiate this normal dyspnoea of pregnancy from pathological dyspnoea, which is associated with peak-flow or spirometry reduction or hypoxaemia.

\section{Effects of pregnancy on asthma}

Asthma may improve, stabilise or worsen during pregnancy. Several reviews [11-13] show, fairly consistently, that approximately one-third of 
gravid asthmatic females are adversely affected, one-third improve and one-third remain stable. Females with severe asthma are more likely to deteriorate, while females with mild asthma usually improve. In a fairly recent study including $>1,700$ pregnant women, exacerbations during pregnancy occurred in $12.6 \%$ of patients initially classified as mild, $25.7 \%$ of patients classified as moderate and $51.9 \%$ of patients classified as severe $(p<0.001)$ [14]. Changes in asthma during pregnancy are often, but not invariably, similar in subsequent pregnancies, and the mechanisms causing these changes are not well understood.

Hormonal changes (particularly increases in progesterone and cortisol levels) may be one of the mechanisms leading to altered control of asthma. Experimental data show that progesterone reduces $\beta$-adrenoceptor responsiveness and increases inflammation.

Altered immune status may also be a mechanism and pregnancy has previously been associated with Thelper (Th) cell type 2 predominance $[15,16]$. This Th2 predominance may accentuate asthma, which is also Th2 driven.

The fact that some females experience an improvement in asthma during pregnancy, while others experience a deterioration in their asth$\mathrm{ma}$, and that different patterns may be observed in consecutive pregnancies in the same mother, makes the mechanisms of contribution of these hormonal or immune changes in pregnancy hard to understand. However, studies in nongravid females have shown that a high proportion of asthmatics have an abnormal concentration of either progesterone or oestradiol, compared with nonasthmatics. These changes are not consistent across the entire group and this may explain different asthma outcomes in pregnancy. There is also recent evidence that the risk of asthma deterioration is higher in the presence of a female foetus [17].

Asthma exacerbations are more frequent at the beginning of the third trimester and some patients become symptomatic during labour. It has been shown that pregnant females who visit the emergency department with acute asthma do not differ from nonpregnant females in the severity or duration of the attack. However, pregnant females are less aggressively treated with corticosteroids and have a threefold increased chance of suffering an ongoing exacerbation after 2 weeks [18]. It is, therefore, important to monitor patients frequently and to treat exacerbations promptly and aggressively. It is also important to use objective tests of severity such as $\mathrm{FEV}$, as almost $10 \%$ of pregnant asthmatics who report that their asthma improved still experience an exacerbation requiring an emergency department visit.

The changes noted in asthma control during pregnancy revert to pre-pregnancy levels within 3 months post-delivery in the majority of women [11].

\section{Effects of asthma on mother and foetus}

\section{Effects on the mother}

Maternal complications associated with uncontrolled asthma include preeclampsia and hypertension, placenta previa, gestational hypertension, hyperemesis gravidarum, vaginal haemorrhage, toxaemia, induced and complicated labour, increased need for a caesarian section and prolonged maternal hospital stay $[3,4]$. Demissie et al. [4] examined records of $>2,000$ asthma and 9,000 normal pregnancies and reported a two-fold increase in hypertensive disorders of pregnancy in gravid asthmatic females. They reported that $7.9 \%$ of gravid asthmatics develop pregnancy-induced hypertension and $4.5 \%$ preeclampsia (the incidence in control pregnancies is $3.9 \%$ and $2.1 \%$, respectively). Nevertheless, data from many studies also show that in appropriately treated and well-controlled asthmatic women, the incidence of adverse outcomes is not significantly different from control pregnancies. These data emphasise the need for optimal treatment of asthma during pregnancy.

\section{Effects on the foetus}

Foetal blood is oxygenated in the human placenta. Oxygenated foetal umbilical vein blood equilibrates with maternal uterine venous blood and, therefore, oxygenated foetal blood $\mathrm{Pa}_{\mathrm{a}_{2}} \mathrm{O}_{2}$ is extremely low, between 3.86-4.92 kPa (29-37 $\mathrm{mmHg}$ ). The foetus tolerates this low $\mathrm{Pa}_{1} \mathrm{O}_{2}$ using several mechanisms that include high foetal haemoglobin concentration, a shift in the oxygenhaemoglobin dissociation curve that favours oxygen delivery to the foetus, high foetal cardiac output and a preferential distribution of foetal cardiac supply to vital organs such as the brain and heart.

Critical maternal respiratory illness, such as an acute exacerbation of asthma, may lead to a fall in maternal $P_{a}, O_{2}$, causing a profound decrease in foetal $\mathrm{Pa}_{\mathrm{a}_{2}} \mathrm{O}_{2}$ and tissue oxygenation. 


\section{Table 1 Step-wise approach to asthma management during pregnancy: NAEPP recommendations}

\begin{tabular}{|c|c|c|c|}
\hline \multirow[t]{2}{*}{ Step } & \multicolumn{2}{|l|}{ Symptoms } & \multirow[t]{2}{*}{ Daily medication for long-term control } \\
\hline & $\begin{array}{cc}\text { Day } & P \\
\text { Night } & P E\end{array}$ & $\begin{array}{l}\text { PEFH or FEV } 1 \text { वा } \\
\text { 'EF variability }\end{array}$ & \\
\hline 4 & $\begin{array}{l}\text { Continuous } \\
\text { Frequent }\end{array}$ & $\begin{array}{l}\leq 60 \% \\
>30 \%\end{array}$ & $\begin{array}{l}\text { Preferred treatment: } \\
\text { High-dose inhaled corticosteroid } \\
\text { AND long-acting inhaled } \beta_{2} \text {-agonist } \\
\text { AND, if needed, corticosteroid tablets or syrup long term } \\
\text { (make repeat attempts to reduce systemic corticosteroid } \\
\text { and maintain control with high-dose inhaled corticosteroid) } \\
\text { Alternative treatment: } \\
\text { High-dose inhaled corticosteroid } \\
\text { AND sustained-release theophylline to serum concentration of } \\
5-12 \mu g \cdot \mathrm{mL}^{-1}\end{array}$ \\
\hline 3 & $\begin{array}{c}\text { Daily } \\
\text { >1 night per week }\end{array}$ & $\begin{array}{c}>60-<80 \% \\
>30 \%\end{array}$ & $\begin{array}{l}\text { Preferred treatment: } \\
\text { Medium-dose inhaled corticosteroid } \\
\text { OR low-dose inhaled corticosteroid } \\
\text { AND long-acting inhaled } \beta_{2} \text {-agonist } \\
\text { If needed (particularly patients with severe exacerbations): } \\
\text { Medium-dose inhaled corticosteroid } \\
\text { AND long-acting } \beta_{2} \text {-agonist } \\
\text { Alternative treatment: } \\
\text { Low-dose inhaled corticosteroid } \\
\text { AND either theophylline or leukotriene receptor antagonist } \\
\text { If needed: } \\
\text { Medium-dose inhaled corticosteroid } \\
\text { AND either theophylline or leukotriene receptor antagonist }\end{array}$ \\
\hline 2 & $\begin{array}{c}>2 \text { days per week but < daily } \\
>2 \text { nights per month }\end{array}$ & $\begin{array}{c}>80 \% \\
20-30 \%\end{array}$ & $\begin{array}{l}\text { Preferred treatment: } \\
\text { Low-dose inhaled corticosteroid } \\
\text { Alternative treatment (listed alphabetically): } \\
\text { Cromolyn, leukotriene receptor antagonist } \\
\text { OR sustained-release theophylline to serum concentration of } \\
5-12 \mu \mathrm{g} \cdot \mathrm{mL}-1\end{array}$ \\
\hline 1 & $\begin{array}{c}<2 \text { days per week } \\
>2 \text { nights per month }\end{array}$ & $\begin{array}{l}>80 \% \\
<20 \%\end{array}$ & $\begin{array}{l}\text { No daily medication needed } \\
\text { Severe exacerbations may occur, separated by long periods of } \\
\text { normal lung function and no symptoms. In this case, a course of } \\
\text { systemic corticosteroids is recommended }\end{array}$ \\
\hline & $\begin{array}{l}\text { ck relief Short-acting bronc } \\
\text { Use of short-acting } \\
\text { in persistent asthn } \\
\text { During exacerbatio } \\
\text { at 20-minute inter } \\
\text { may be needed }\end{array}$ & $\begin{array}{l}\text { ichodilator: } 2- \\
\text { g inhaled } \beta_{2}^{-} \\
\text {ma) may indi } \\
\text { ins, intensity } \\
\text { ervals or a sing }\end{array}$ & $\begin{array}{l}\text { Ifs short-acting inhaled } \beta_{2} \text {-agonist as needed for symptoms } \\
\text { ist >twice a week in intermittent asthma (daily, or increasing use } \\
\text { a need to initiate (increase) long-term control therapy } \\
\text { atment will depend on severity of exacerbation; up to } 3 \text { treatments } \\
\text { ebuliser treatment as needed. Course of systemic corticosteroid }\end{array}$ \\
\hline
\end{tabular}

According to NAEPP guidelines: low-dose budesonide (BUD) <600 $\mu$; medium-dose BUD 600-1,200 $\mu$; high-dose $B U D>1,200 \mu \mathrm{g}$. According to the Canadian Medical Association: low-dose beclomethasone (BDP) $<500 \mu \mathrm{g}$; low-dose BUD <400 $\mu$; medium-dose BDP 500-1,000 $\mu$; medium-dose BUD 400-800 $\mu$; high-dose BDP >1,000 $\mu$; highdose BUD >800 $\mu \mathrm{g}$. PEF: peak expiratory flow. \#: \% of personal best; 9 : \% predicted. Value expressed as \% pred are good markers of severity, while values given as \% of personal best give a good measure of control and are more important in decision regarding treatment adjustments. Table adapted from [2], with permission from the publisher.

A recently published experimental animal study showed that when the maternal arterial oxygen saturation $\left(\mathrm{S}_{1} \mathrm{O}_{2}\right)$ falls from 98 to $\sim 58 \%$, foetal $\mathrm{Sa}_{1} \mathrm{O}_{2}$ falls from 62 to $27 \%$ [19]. Furthermore, maternal compensatory mechanisms will tend to maintain oxygenation and blood flow to maternal vital organs at the expense of uterine blood flow and foetal oxygenation. Therefore, foetal distress can occur even in the absence of maternal hypoxia or hypotension.

Foetal complications in the pregnancies of females with uncontrolled asthma include increased risk of perinatal mortality, intrauterine growth retardation, low birth weight, pre-term birth and neonatal hypoxia [4, 20]. Demissie et al. [4] reported slightly increased odds ratios 
(1.32-1.44) for small-for-dates, low weight and longer post-delivery hospital stay.

\section{Asthma management during pregnancy}

The goals of asthma therapy in pregnancy focus on the wellbeing of both mother and foetus. More specifically the goals are to:

$>$ control daytime and nocturnal symptoms

$>$ maintain normal or best pulmonary function

$>$ maintain normal activity levels; prevent

acute exacerbations

$>$ avoid adverse effects of medication

$>$ ensure normal foetal maturation and the birth of a healthy baby.

The management plans are successful if they are based on: accurate estimation of severity; close monitoring; patient education; avoidance of asthma triggers; and tailored pharmacological treatment that is adjusted as needed, in a stepwise manner according to guidelines.

Estimation of severity and monitoring of disease control and of responses to treatment are based on patient symptoms, peak expiratory flow and simple spirometry measurements and the same principles apply both to gravid and nongravid patients. In pregnancy, moreover, it is important to integrate asthma care with obstetric care, especially in cases of more severe asthma or complicated pregnancy. It is also very important to avoid triggering factors where possible. The current NAEPP report on asthma and pregnancy [2] stresses the importance of aggressive asthma treatment in pregnancy, which should equal the treatment of nonpregnant individuals. However, when choosing any drug in pregnancy, the therapeutic benefits must be weighed against possible risks to the mother and foetus.

All guidelines on asthma and pregnancy stress that, during pregnancy, inhaled medications and older drugs with a long history of use and well-documented studies are preferred.

A brief description of the step-wise approach

\section{Table 2 US FDA ratings for prescribing in pregnancy}

Category Interpretation
Adequate, well-controlled studies in pregnant women have not shown an increased
risk of abnormalities to the foetus in any trimester of pregnancy
B Animal studies have revealed no evidence of harm to the foetus; however, there are
no adequate and well-controlled studies in pregnant women
OR
Animal studies have shown an adverse effect, but adequate and well-controlled
studies in pregnant women have failed to demonstrate a risk to the foetus in any
trimester
Animal studies have shown an adverse effect and there are no adequate and well-
controlled studies in pregnant women
OR
No animal studies have been conducted and there are no adequate and well-
controlled studies in pregnant women
Adequate well-controlled or observational studies in pregnant women have
demonstrated a risk to the foetus; however, the benefits of therapy may outweigh
the potential risk. For example, the drug may be acceptable if needed in a life-
threatening situation or serious disease for which safer drugs cannot be used or are
ineffective
Adequate well-controlled or observational studies in animals or pregnant women
have demonstrated positive evidence of foetal abnormalities or risks
The use of the product is contraindicated in women who are or may become pregnant

to asthma management as recommended by the NAEPP report and the GINA and British Thoracic Society (BTS) guidelines is given in table 1. In the latest GINA guidelines, management strategies are based on disease control and regardless of disease severity. Treatment is intensified when control is not achieved or decreased when control is achieved and maintained.

The effectiveness of medications is assumed to be the same in pregnant women as in nonpregnant women, although there are no studies that test this assumption directly.

\section{Notes on specific medications used in asthma}

The Food and Drug Administration (FDA) in the USA has published guidelines for prescribing during pregnancy (reviewed in [21]). Drugs are

\section{Recommendations for managing asthma during pregnancy}

$>\quad$ It is important to reassure the patient about the safety of asthma medication and provide education about self-care strategies

$>\quad$ Inhaled steroids and $\beta$-agonists are the preferred controller and reliever medications for use during pregnancy

$>\quad$ It is important to monitor symptoms and lung function, make appropriate adjustments in therapy, and prevent or promptly treat exacerbations to ensure normal blood oxygenation and oxygen supply to the foetus (maternal $\mathrm{Sa}_{1} \mathrm{O}_{2}>95 \%$ )

$>\quad$ The obstetric care provider should also be involved in asthma care and monitor asthma symptoms during regular prenatal visits 
categorised into groups $A, B, C, D$ and $X$ according to safety data based on animal and human gestational studies (table 2). Drugs in category $X$ are contraindicated for use during pregnancy. No asthma medication is currently classified as category A (both animal and human studies show no risk to the foetus). Most asthma medications are classified as class B and C (no risk is shown and benefit from medication use outweighs risk; see details in table 2).

The highest risk in the pregnancy of an asthmatic female is due to uncontrolled asthma and this should be stressed to the patient. The physician should be ready to discuss with the patient potential risks from medication, but at the same time reassure the patient that there are a number of studies showing that most asthma medications and, in particular, inhaled glucocorticosteroids and shortacting $\beta_{2}$-agonists are not associated with an increased incidence of foetal abnormalities. Moreover, inhaled glucocorticosteroids have been shown to prevent exacerbations of asthma in pregnancy [18], and hence prevent foetal hypoxia and adverse outcomes. Providing education and reassuring the patient about the safety of medications is pivotal for successful management [22] and most patients need the obstetrician's reassurance as well as the respiratory care provider's.

\section{$\beta_{2}$-Adrenergic agonists}

Selective $\beta_{2}$-agonists appear to be safe for use during pregnancy and inhaled preparations are extensively used. Large studies have not shown any risk associated with their use $[22,23]$. Terbutaline is classified as class B while all other

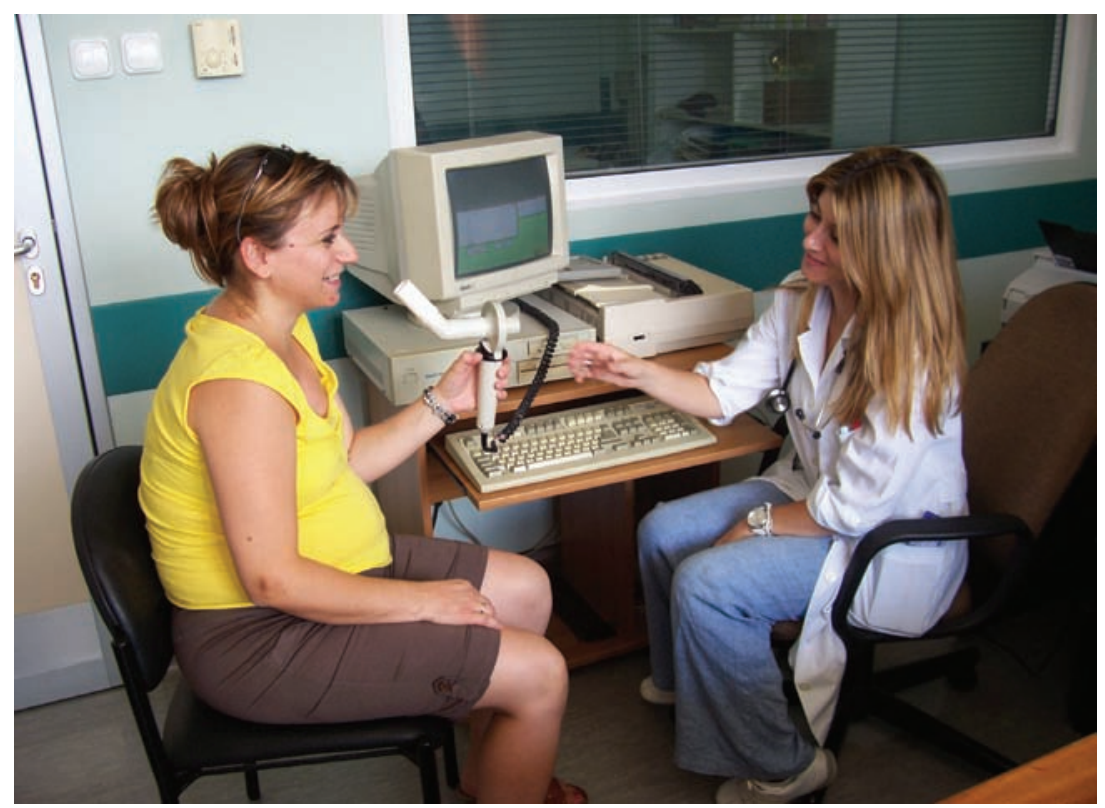

$\beta$-agonists are classified as class C. Salbutamol is the most widely used and is recommended by the NAEPP guidelines. There are very few data on the use of long-acting $\beta_{2}$-agonists, but there is no evidence of risk, and their use is recommended in moderate and severe asthma as daily controller medication in combination with inhaled steroids. The use of adrenaline is not recommended, as its use shows no advantages over aerosolised treatment and it may cause vasoconstriction in the uterus and reduce uteroplacental blood flow. Systemic $\beta_{2}$-agonists are only very rarely needed. When used, they may cause tachycardia, hyperglycaemia and tremor. They may also inhibit uterine contraction and their use is not recommended near term, unless they are specifically needed for their tocolytic effects.

\section{Steroids}

Inhaled steroids are recommended for use during pregnancy and many studies show no risk to the foetus [23-25]. Most inhaled steroids are classified as class $C$ according to the FDA. Budesonide is the only inhaled steroid classified as $B$ in the FDA ratings and it is recommended by the NAEPP guidelines. Data from a large study published in 1999 [26] show no increased risk of congenital malformations in 2,014 infants of females who received budesonide in early pregnancy. Although there are fewer data regarding other inhaled steroids, there is no evidence of risk from any studies. If asthma, and particularly severe asthma, is controlled with a specific preparation, then it is suggested that the patient should continue its use.

Oral steroids are used for the treatment of a number of inflammatory conditions and, therefore, they have been used fairly extensively during pregnancy. Potential foetal adverse effects associated with the use of oral steroids include cleft lip or cleft palate when used in the first trimester, low birth-weight and prematurity (the incidence of cleft palate in the general population is $0.1 \%$ and in women receiving oral steroids 0.3\%) [27]. Data from large human studies show that oral steroids may be associated with increased incidence of pre-term delivery, pre-eclampsia or a slight decrease in the weight of the newborn [26-28]. Conversely, the dose and timing of steroids as well as the severity of asthma are not very well documented in those studies, and low birth-weight may be the result of poor asthma control requiring oral steroid use and not the use of medication itself. Studies 
show that severe asthma and asthma exacerbations are not well controlled without oral steroids [18] and uncontrolled asthma is a risk to both mother and foetus. The use of oral steroids during pregnancy should, therefore, not be withheld. On the contrary, when required, they should be used promptly and in adequate doses (tables 1 and 3).

\section{Cromoglycates}

Sodium cromoglycate is considered safe for use during pregnancy, it is listed as class B and is included in the NAEPP report [2], but it requires very frequent dosing and it is not recommended as first-line treatment. Less information is available on the use of nedocromil.

\section{Methylxanthines}

The use of both theophylline and aminophylline is considered safe during pregnancy, although it is not the treatment of choice [2]. Similarly to $\beta_{2^{-}}$ agonists, theophylline may inhibit contractions, probably through increased cyclic adenosine monophosphate levels. It may cause tachycardia and irritability in the foetus. Theophylline has not been shown to induce a risk of major congenital malformations or adverse perinatal outcomes, but it needs close monitoring and is inferior to inhaled steroids in the prevention of exacerbations, so it is not recommended. If used, target plasma levels should be kept lower during pregnancy, between $5-12 \mathrm{mg} \cdot \mathrm{mL}^{-1}$.

\section{Anticholinergic agents}

Anticholinergic agents are not first-line medications in asthma and very limited data exist on their use in human pregnancies. If needed, ipratropium is considered safe for use during pregnancy and is classified in FDA category B [5].

\section{Leukotriene antagonists}

There are very limited data about the use of leukotriene antagonists in human pregnancies, but studies have not shown risks and they are classified in category B. Because there are limited human data, although animal studies do not show any risks, they are not yet recommended as firstline treatment. Furthermore, GINA guidelines recommend inhaled steroids as the first-line

\section{Table 3 Dosing of rescue $\beta$-agonists and oral steroids during severe exacerbations}

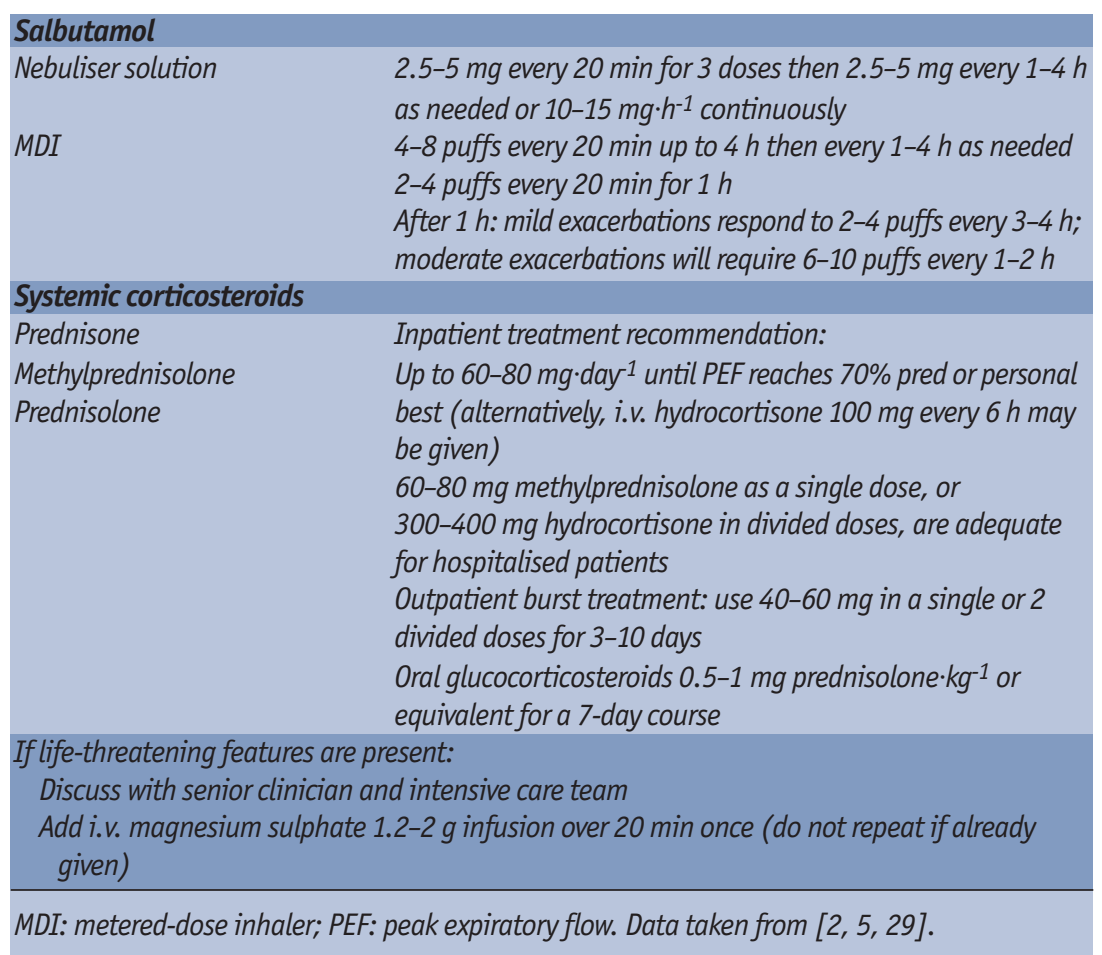

treatment option. The BTS guidelines recommend that leukotriene antagonists should not be commenced during pregnancy, but that they may be continued in women who have demonstrated significant improvement in asthma control with their use.

\section{Anti-immuniglobulin E}

Animal studies do not show teratogenic effects, but very limited data exist in humans. It is classified as class $B$ by the FDA, but is not mentioned in the 2005 BTS or NAEPP guidelines on asthma and pregnancy.

\section{Other medications}

Antihistamines are often needed for the treatment of upper airway symptoms. No risk has been shown by their use, but again older medications are preferred, and loratadine and cetirizine are the ones recommended by the NAEPP guidelines.

\section{Components of asthma treatment management}

Assessment and monitoring of asthma, including objective measures of pulmonary function

Control of factors contributing to asthma severity

Patient education

A stepwise approach to pharmacotherapy 


\section{Table 4 FDA use-in-pregnancy ratings for specific asthma drugs}

\begin{tabular}{|c|c|c|}
\hline Drug class & Drug & FDA category \\
\hline \multirow[t]{7}{*}{$\beta$-Adrenergic agonists } & Salbutamol (Albuterol) & $C$ \\
\hline & Terbutaline & $B$ \\
\hline & Formoterol & C \\
\hline & Salmeterol & C \\
\hline & Bitolterol & C \\
\hline & Pirbuterol & C \\
\hline & Adrenaline & C \\
\hline \multirow[t]{2}{*}{ Anticholinergic drugs } & Ipratropium & $B$ \\
\hline & Tiotropium & C \\
\hline \multirow[t]{2}{*}{ Methylxanthines } & Theophylline & C \\
\hline & Aminophylline & C \\
\hline \multicolumn{3}{|l|}{ Corticosteroids } \\
\hline \multirow[t]{6}{*}{ Inhaled } & Beclomethasone & C \\
\hline & Budesonide & $B$ \\
\hline & Fluticasone & C \\
\hline & Triamcinolone & C \\
\hline & Flunisolide & C \\
\hline & Mometasone & C \\
\hline \multirow[t]{2}{*}{ Oral } & Prednisone & $B$ \\
\hline & Prednisolone & C \\
\hline \multirow[t]{2}{*}{ Cromoglycates } & Cromolyn sodium & $B$ \\
\hline & Nedocromil & $B$ \\
\hline \multirow[t]{3}{*}{ Agents affecting leukotrienes } & Zafirlukast & $B$ \\
\hline & Montelukast & $B$ \\
\hline & Zileuton & C \\
\hline \multirow[t]{5}{*}{ Antihistamines } & Chlorpheniramine & $B$ \\
\hline & Astemizole & C \\
\hline & Loratadine & $B$ \\
\hline & Fexofenadine & C \\
\hline & Cetirizine & $B$ \\
\hline Decongestants & Pseudoephedrine & C \\
\hline
\end{tabular}

Decongestants are best avoided during pregnancy and other classes of medication such as nasal steroids, external dilators and local antihistamines should be tried first.

Antibiotics may be used for the treatment of exacerbations due to infections. The FDA has also classified the safety of use of various antibiotics during pregnancy.

The safest and most widely used antibiotics include amoxicillin, erythromycin, azithromycin (all classified as FDA B class) and clarithromycin (FDA C class). Cephalosporins may also be used.
Table 4 summarises FDA ratings for use of asthma medications during pregnancy

\section{Acute exacerbations}

Acute exacerbations should be treated aggressively in order to avoid foetal hypoxia. In the case of a severe or sustained exacerbation, treatment includes inhaled and systemic steroids, oxygen supplementation, frequent $\beta_{2}$-agonist dosing and, if necessary, hospital admission and intensive care. Maternal $\mathrm{Sa}_{1} \mathrm{O}_{2}$ should be $>95 \%$. Foetal signs of distress, such as reduced kicking, should be monitored and an ultrasound is advised.

\section{Breastfeeding and asthma}

Women with asthma should be encouraged to breastfeed. The risk of atopic disease developing in the child of an asthmatic woman is about one in 10, or one in three if both parents are atopic. This risk may be reduced by breastfeeding. All inhaled preparations, oral steroids and methylxanthines are safe when breastfeeding [30].

\section{Conclusions}

In conclusion, pregnant patients with asthma should be advised that the greater risk to their baby lies with poorly controlled asthma, and the safety of most modern asthma treatments should be discussed and stressed. A good patient/healthcare professional relationship, patient education, frequent monitoring and tailored treatment should ensure excellent outcomes. Prescribing during pregnancy should follow the same stepped approach to treatment and inhaled and older medications with documented safety are preferred. 


\section{Educational questions}

1. During pregnancy, the physician should be alerted when he finds which of the following?

a) A 30\% increase in minute ventilation.

b) A fall in FRV and RV.

c) A $30 \%$ drop in FEV1.

d) $\mathrm{Sa}_{1} \mathrm{O}_{2} 94 \%$.

e) Nasal obstruction.

2. In the first trimester of pregnancy, which of the following is/are true?

a) Inhaled steroids are considered safe.

b) Oral steroids should be withheld.

c) $\beta$-Agonists should be withheld.

3. During an exacerbation, which of the following is/are true?

a) Treatment doses should be $50 \%$ less than those given to nonpregnant patients.

b) $\mathrm{Sa}_{1} \mathrm{O}_{2}>95 \%$ should be maintained.

c) Nasal obstruction is a sign of an eminent exacerbation.

d) For outpatient rescue treatment, oral steroids should be given in doses of $30-60 \mathrm{mg}$.

\section{References}

1. Kwon HL, Belanger K, Bracken MB. Asthma prevalence among pregnant and child bearing-aged women in the United States: estimates from national health surveys. Ann Epidemiol 2003; 13: 317-324.

2. NAEPP expert panel report. Managing asthma during pregnancy: recommendations for pharmacologic treatment-2004 update. J Allergy Clin Immunol 2005; 115: 34-46.

3. Wen SW, Demissie K, Liu S. Adverse outcomes in pregnancies of asthmatic women: result from a Canadian population. Ann Epidemiol 2001; 11: 7-12.

4. Demissie K, Breckenridge MB, Rhoads GG. Infant and maternal outcomes in the pregnancies of asthmatic women. Am J Respir Crit Care Med 1998; 158: 1091-1095.

5. Global initiative for asthma (GINA). Global strategy for asthma management and prevention. NHLBI/WHO Report. Bethesda, National Institutes of Health, National Heart, Lung and Blood Institute. NIH Publication: 02-3659. Updated 2006. www.ginasthma.org

6. Mortola JF. Hormonal changes during normal pregnancy and their consequences. In: Schatz M, Zeiger RS, Claman HN, eds. Asthma and Immunologic Diseases in Pregnancy and Early Infancy. New York, Marcel Dekker, 1998; pp. 3-25.

7. Bonica JJ. Maternal respiratory changes during pregnancy and parturition. In: Marx GF, ed. Parturition and Perinatology. Philadelphia, F.A. Davis, 1973; pp. 2-19.

8. Cousins L, Catanzarite VA. Fetal oxygenation, acid-base balance, and assessment of well-being in the pregnancy complicated by asthma or anaphylaxis. In: Schatz M, Zeiger RS, Claman HN, eds. Asthma and Immunologic Diseases in Pregnancy and Early Infancy. New York, Marcel Dekker, 1998; pp. 27-56.

9. Wise RA. Pulmonary function during pregnancy. In: Schatz M, Zeiger RS, Claman HN, eds. Asthma and Immunologic Diseases in Pregnancy and Early Infancy. New York, Marcel Dekker, 1998; pp. 57-72.

10. Juniper EF, Daniel EE, Roberts RS, Kline PA, Hargreave FE, Newhouse MT. Improvement in airway responsiveness and asthma severity during pregnancy. A prospective study. Am Rev Respir Dis. 1989; 140: 924-931.

11. Schatz $M$, Harden $K$, Forsythe $A$, et al. The course of asthma during pregnancy, postpartum and with successive pregnancies: a prospective analysis. J Allergy Clin Immunol 1998; 81: 509-517.

12. Schatz M. Interrelationships between asthma and pregnancy: a literature review. J Allergy Clin Immunol 1999; 103: S330-S336.

13. Murphy VE, Gibson PG, Smith R, Clifton VL. Asthma during pregnancy: mechanisms and treatment implications. Eur Respir J 2005; 25: 731-750.

14. Schatz M, Dombrowski MP, Wise R, et al. Asthma morbidity during pregnancy can be predicted by severity classification. J Allergy Clin Immunol 2003; 112: 283-288.

15. Wegmann TG, Lin H, Guilbert L, Mosmann TR. Bidirectional cytokine interactions in the maternal-fetal relationship: is successful pregnancy a TH2 phenomenon? Immunol Today 1993; 14: 353-356.

16. Saito S, Sakai M, Sasaki Y, Tanebe K, Tsuda H, Michimata T. Quantitative analysis of peripheral blood Th0, Th1, Th2 and the Th1:Th2 cell ratio during normal human pregnancy and preeclampsia. Clin Exp Immunol 1999; 117: 550-555.

17. Murphy VE, Gibson PG, Giles WB, et al. Maternal asthma is associated with reduced female fetal growth. Am J Respir Crit Care Med 2003; 168: 1317-1323.

18. Cydulka RK, Emerman CL, Schreiber D, Molander KH, WoodruffR, Camargo Jr CA. Acute asthma among pregnant women presenting to the emergency department. Am J Respir Crit Care Med 1999; 160: 887-892.

19. Jellyman JK, Gardner DS, Edwards CM, Fowden AL, Giussani DA. Fetal cardiovascular, metabolic and endocrine responses to acute hypoxaemia during and following maternal treatment with dexamethasone in sheep. J Physiol 2005; 567: 673-688.

20. Schatz M, Zeiger RS, Hoffman CP, et al. Perinatal outcomes in the pregnancies of asthmatic women: a prospective controlled analysis. Am J Respir Crit Care Med 1995; 151: 1170-1174.

21. Gaga M, Siafakas NM. Special considerations in asthma. In: Asthma. Eur Respir Mon 2003; 23: 293-311.

22. Murphy VE, Gibson PG, Talbot PI, Kessell CG, Clifton VL. Asthma self-management skills and the use of asthma education during pregnancy. Eur Respir J 2005; 26: 435-441.

23. Wendel PJ, Ramin SM, Barnett-Hamm C, Rowe TF, Cunningham FG. Asthma treatment in pregnancy: a randomized controlled study. Am J Obstet Gynecol 1996; 175: 150-154.

24. Schatz M, Zeiger RS, Harden K, Hoffman CC, Chilingar L, Petitti D. The safety of asthma and allergy medications during pregnancy. J Allergy Clin Immunol 1997; 100: 301-306.
Useful weblinks

Managing asthma during pregnancy: recommendations for phamacologic treatment: Update 2004.

www.nhlbi.nih.gov/health/prof/ lung/asthma/astpreg.htm

Boulet LP, Becker A, Bérabé D,

Bveridge R, Erbst $P$, the Canadian Asthma Consensus Group.

Canadian asthma consensus

report, 1999. CMAJ 1999; 161:

Suppl. 1, S1-S62.

www.cmaj.ca/cgi/reprint/161/11

_suppl_1/s1

Global Initiative for Asthma

website.

www.ginasthma.org

British Guideline on the

Management of Asthma.

www.enterpriseportal2.co.uk/file store/bts/asthmaupdatenov05. $p d f$ 
25. Kallen B, Rydhstroem H, Aberg A. Congenital malformations after the use of inhaled budesonide in early pregnancy. Obstet Gynecol 1999; 93: 392-395.

26. Namazy J, Schatz M, Long L, et al. Use of inhaled steroids by pregnant asthmatic women does not reduce intrauterine growth. J Allergy Clin Immunol 2004; 113: 427-432.

27. Park-Wyllie L, Mazzotta P, Pastuszak A et al. Birth defects after maternal exposure to corticosteroids: prospective cohort study and meta-analysis of epidemiological studies. Teratology 2000; 62: 385-392.

28. Bracken MB, Triche EW, Belanger K, Saftlas A, Beckett WS, Leaderer BP. Asthma symptoms, severity, and drug therapy: a prospective study of effects on 2205 pregnancies. Obstet Gynecol 2003; 102: 739-752.

29. British Guideline on the Management of Asthma: a National Clinical Guideline. www.enterpriseportal2.co.uk/filestore/bts/asthmaupdatenov05.pdf. Date last accessed: December 13, 2006. Date last updated: November 2005.

30. Nelson-Piercy C. Asthma in pregnancy. Thorax 2001; 56: 325-328.

\section{Suggested answers}

1. $c$ and $d$

2. a

3. $b$ and $d$

A substantial increase in minute ventilation and a fall in functional residual capacity and RV are normal during pregnancy. Nasal obstruction is also common and is not a sign of worsening of asthma. FEV1, however, is preserved and therefore a fall in FEV1 is a pathological finding that should alert the physician. There are many large studies showing that inhaled steroids and $\beta$-agonists are safe and can be used in pregnancy, even in the early months. Although oral steroids have been associated with malformations and in particular cleft lip or palate, the risk shown in human pregnancies is very low and their usefulness outweighs this risk. So, in case of exacerbations or of severe disease, they are recommended for use even in the first trimester of pregnancy. Dosing of medications during an exacerbation should equal that given to nonpregnant patients. $\mathrm{Sa}_{1} \mathrm{O}_{2}$ should always be maintained above $95 \%$, as lower maternal saturation causes foetal hypoxia. 